\title{
Lead-free Solders: Reliability, an Ongoing Saga
}

\author{
Srinivas Chada
}

It has been half a decade since the legislated ban on lead in electrical and electronic equipment throughout the European Union according to Restriction of the use of certain Hazardous Substances in Electrical and Electronic Equipment directives. ${ }^{1}$ In response, "Management Methods for Prevention and Control of Pollution from Production of Electronic and Information Products" ${ }^{2}$ was drafted by China, while in the United States, California legislated electronic waste recycling. ${ }^{3}$ In response, the Electronic Packaging/ Interconnection Materials Committee of the TMS Electronic, Magnetic \& Photonic Materials Division organized a series of symposia on lead-free and lead-bearing solders. The results were published $^{4-17}$ in JOM and special issues of the Journal of Electronic Materials. Continuing the trend, the " $\mathrm{Pb}$-Free Solders and Other Materials for Emerging Interconnect and Packaging Technologies" symposium was held February 27-March 3, 2011 at the TMS Annual Meeting. At the symposium organized by Idranath Dutta et al., more than 60 papers dealing with next generation packaging, whisker growth, alloy and microstructural development, thermomechanical behavior, electromigration, processing and reliability for lead-free solders were presented. The four papers selected for this issue deal with tin whiskers, three-dimensional (3-D) interconnects, and polymeric thermal interfaces.

Pure Sn finish is fast becoming the most economical way of replacing Sn$\mathrm{Pb}$ solder on lead frames. However, plated pure Sn can nucleate and grow whiskers that are detrimental to the operation of the devices and printed circuit board assembly. In the first paper J.W. Osenbach presents the variety of different Sn whisker morphologies reported in literature since late 1940s when the whisker growth was first identified and published.

The paper by E. Chason et al. throws light on the main driving force for whisker formation, namely, compressive stresses from intermetallic compound growth. To better understand the whisker growth mechanism, the authors studied the effect of Sn layer properties such as grain size, thickness, microstructure, etc. on the evolution of whiskers.

In the quest for miniaturization and faster clock speeds electronic packaging has gone vertical by stacking die to maximize real estate. Through-silicon Via (TSV) is one of the enabling technology trends in 3-D packages. However, these vertically stacked packages are fraught with reliability concerns due to contrasting properties of $\mathrm{Cu}$ filled TSVs and rigid silicon die. I. Dutta et al. discuss the results that illustrate the reliability challenges facing the 3-D packages with TSVs.

The last paper from D.F. Rae et al. focuses on the thermal interface materials that improve the heat dissipation from devices to improve reliability and extend device life. In this paper the effect of metal filler material properties and processing on the overall thermal properties of a polymeric thermal bond-line are discussed.

\section{References}

1. Industry Council for Electronic Equipment Recycling, Rivington Street, London, www.icer.org.uk. 2. "Management Methods for Prevention and Control of Pollution from Production of Electronic and Information Products," English translation of draft comments for China ROHS (July 2003).

3. "Electronics Waste Recycling Act" of 2003 (California S.B. 20/50) (California Department of Resources Recycling and Recovery, Sacramento, CA), w ww.calrecycle.ca.gov/electronics/act2003/.

4. Special Issue on Packaging and Soldering Technologies for Electronic Interconnects, J. Electron. Mater., 29 (2000), pp. 1111-1298.

5. JOM, 53 (6) (2001), pp. 16-41.

6 . Special Issue on Lead-Free Solder Materials and Soldering Technologies, J. Electron. Mater., 30 (2001), pp. 1049-1270.

7. JOM, 54 (6) (2002), pp. 25-40.

8. Special Issue on Lead-Free Solders and Processing Issues in Microelectronic Packaging, J. Electron. Mater., 1 (2002), pp. 1129-1308.

9. JOM, 55 (6) (2003), pp. 49-69.

10. Special Issue on Lead-Free Solders and Processing Issues in Microelectronic Packaging, J. Electron. Mater., 2 (2003), pp. 1359-1522.

11. JOM, 56 (6) (2004), pp. 33-54.

12. Special Issue on Lead-Free Solders and Processing Issues in Microelectronic Packaging, J. Electron. Mater., 33 (2004), pp. 1411-1618.

13. Special Issue on Lead-Free Solder Implementation: Reliability, Alloy Development, New Technology, J. Electron. Mater., 35 (2006), pp. 2073-2135.

14. Special Issue on Pb-Free Electronic Solders: Alloy Design, Characterization, and Service Reliability, J. Electron. Mater., 37 (2008), pp. 1-133.

15. Special Issue on Emerging Interconnect and Packaging Technologies, J. Electron. Mater., 38 (2009), pp. 209-378

16. Special Issue on Pb-free Solders, J. Electron. Mater., 38 (2009), pp. 2427-2786.

17. Special Issue on Pb-Free Solders and Emerging Interconnect and Packaging Technologies, J. Electron. Mater., 39 (2010), pp. 2503-2731.

Srinivas Chada is a Technical Services ManagerElectronics, at Henkel Electronic Materials, LLC, Irvine, CA. He is the advisor to JOM from the Electronic Packaging/Interconnection Materials Committee of the Electronic, Magnetic \& Photonic Materials Division of TMS.

\section{Srinivas Chada is a TMS Member!}

To read more about him, turn to page 9. To join TMS, visit www.tms.org/Society/Membership.aspx.

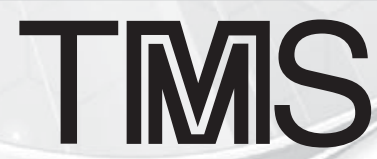

